\title{
A "contação" de histórias como estratégia de marketing social em uma IES para letramento literário de moradores de baixa renda de comunida- des cariocas
}

\author{
Rosa Valim (UniCarioca/PUC-RJ/EICOS/UFRJ) \\ Lucas Alves (UniCarioca)
}

\section{Resumo}

O presente artigo tem por propósito relatar a estratégia de marketing social adotada pela UniCarioca, IES (Instituição de Ensino Superior) situada no Rio de Janeiro, para desenvolvimento e implementação do projeto Contadores de Histórias, ocorrido durante o ano de 2015. Este projeto, uma iniciativa do EPM/ UniCarioca (Escritório de pratica de Marketing/ UniCarioca) e do NASA/UniCarioca (Núcleo de Ação Socioambiental/ UniCarioca) em parceria com o Programa Rio Mais Social, perpassou pela área da educação, pois procurou estimular o hábito de leitura em aproximadamente 2.550 pessoas de todas as idades, pertencentes a 14 comunidades do Rio de Janeiro. Ao propiciar o contato destas diferentes pessoas com a leitura, o projeto atuou com letramento literário (clássicos da literatura brasileira), em prol da ampliação de suas bagagens culturais e, com isso, buscou viabilizar o desenvolvimento de suas autoestimas e, por conseguinte, a ampliação de seus horizontes de vida. Impactos deste projeto foram sentidos rapidamente na postura dos participantes, mas certamente os maiores impactos só serão percebidos com o tempo. Afinal, o conhecimento adquiridos pelos participantes deste projeto ampliou o nível de desenvolvimento real e, por conseguinte, o nível de desenvolvimento potencial destes. Trabalhou-se aqui com modelo metodológico polissêmico, pois se conjugou, neste trabalho, modelo de Trabalho Social Comunitário, modelo de narrativa autobiográfica e modelo ecológico. Impactos deste projeto também foram percebidos nos estudantes da UniCarioca, bem como na Instituição.

Ao integrarem este projeto social - assumindo responsabilidades diversas ao longo do processo - os alunos reforçaram empiricamente aspectos explícitos do aprendizado acadêmico, desenvolveram aspectos diversos associados à sociabilidade e amadureceram como cidadãos. Já a Instituição acabou por reforçar seu compromisso com a inclusão social e com uma educação transformadora.

Palavras-Chave: Educação; Marketing Social; Leitura; Contação de histórias; Letramento.

\begin{abstract}
This article purposes to report the social marketing strategy adopted by Unicarioca, IES (Higher Education Institution) located in Rio de Janeiro, for the development and implementation of a Storytelling Project, occurred during the year of 2015. This Project is an initiative by EPM/UniCarioca (Marketing Practice Office/ UniCarioca) and NASA/UniCarioca (Socio-Environmental Action Nucleus /UniCarioca) in partnership with the Program Rio Mais Social (Rio More Social), encompassing the area of education insofar as it sought to encourage the habit of reading in approximately 2,550 people of all ages from 14 communities in Rio de Janeiro. By providing reading contact to different profiles of people, the project worked with a literature literacy strategy (using Brazilian literature classics), thus favoring the extension of their cultural background and seeking to facilitate the development of their self-esteem and, consequently, the expansion of their lives horizon. This project is impact was felt quickly in the participants' attitude, but certainly the biggest impacts will only be perceived over time, after all, the knowledge acquired by the participants of this project expanded their real and potential development levels. A polysemic methodological model was used, given its multifaceted Social Community Work conjugated with a self-biographical narrative and ecological model. This project is impacts were also perceived by Unicarioca students as well as by the institution itself. By integrating this social project - incorporating several responsibilities throughout the process - students have empirically strengthened explicit aspects of their academic learning, developing various aspects associated with sociability and maturity as citizens. Conversely,
\end{abstract}


the institution eventually strengthened its commitment to social inclusion and to transformative education.

Keywords: Education; Social Marketing; Reading; Story Telling; Literacy.

\section{Introdução}

Tendo em mente que aprendemos não apenas para nos adaptar, mas, sobretudo, para transformar a realidade, para nela intervir, recriando-a (FREIRE, 1988, p.76), esta pesquisa procurou, com sensibilidade, transformar a realidade imediata a partir das ações realizadas.

A ideia de estruturar e executar este projeto de marketing social - intitulado Projeto Contadores de Histórias - surgiu em abril de 2015. A motivação partiu de um grupo de alunos de Marketing da UniCarioca e encontrou receptividade no EPM/ UniCarioca (Escritório de pratica de Marketing/ UniCarioca) e no NASA/ UniCarioca (Núcleo de Ação Socioambiental/ UniCarioca).

Inicialmente, definiram-se contornos para o projeto, a saber: (1) o projeto teria como pilares quatro áreas - logística, finanças, marketing/comunicações e leitura/operações ("contação" de histórias); (2) para dar conta da complexidade imaginada, seria necessário conseguir a adesão de outros estudantes universitários voluntários de diversas áreas (não apenas oriundos do curso de marketing); (3) para dar conta da complexidade imaginada, seria necessário conseguir a adesão também de pessoa jurídica ligada à área social e (4) o projeto - idealmente - deveria percorrer diversas comunidades cariocas.

Ezequiel Theodoro da Silva (SILVA, 2012) afirma que (...) a leitura é o principal instrumento, se não o único que nos resta, para sustentar uma educação emancipada, combater o besteirol institucionalizado e apontar para outras formas de convivência social. Foi com este norte que o projeto aqui relatado foi desenhado e implementado.

\section{O Projeto}

\section{A estruturação}

Edital interno - na UniCarioca - para promover a adesão de alunos interessados foi elaborado e posteriormente divulgado (em maio de 2015). Foram 15 dias de árduo trabalho para que o documento fosse escrito e divulgado. Durante esse período, o escopo do material literário a ser utilizado nas "contações" de história foi definido - o corte utilizado foi o seguinte: (1) o material deveria obrigatoriamente pertencer à literatura brasileira; (2) as histórias precisavam traduzir lições de moral ou histórias inspiradoras e (3) o material a ser utilizado deveria ser angariado a partir de doações espontâneas dos alunos de graduação da UniCarioca.

Certificado de horas por realização de atividade complementar, ajuda de custo para transporte e alimentação e treinamento e capacitação foram alguns dos benefícios oferecidos em edital aos que se voluntariassem e fossem aprovados. O número de inscrições - via formulário - foi expressivo, e a tarefa de seleção dos voluntários foi árdua. Um dos fatores que auxiliou o processo de seleção dos mais aptos foi a resposta dada pelos inscritos a um dos itens do formulário: "explique o porquê de você querer participar deste projeto”. Destacaram-se as respostas que revelassem preocupação com o bem comum ou traduzissem a preocupação para com comportamento ético/moral.

As inscrições superaram as expectativas - foram mais de 500 inscritos. Voluntários para as diversas áreas previstas foram selecionados e capacitados, totalizando 70, dez a mais do que havia sido estimado no início do projeto. Previa-se uma possível desistência de $10 \%$ dos selecionados ao longo do processo por conta de 
questões pessoais diversas, visto que trabalhar de maneira voluntária, mesmo que em projeto temporário e de maneira parcial, não é fácil ou possível para qualquer pessoa.

Para além, fechou-se parceria com o Rio Mais Social, um órgão público municipal responsável por mapear áreas da cidade com o intuito de viabilizar/consolidar práticas/ações sociais com demandas necessárias.

Com a adesão do Rio Mais Social, o projeto ganhou a injeção de ânimo necessária para projetar-se por diversas comunidades (14 ao todo), como desejado. Esta parceria foi estratégica, pois foi graças a ela que se pôde - em segurança e também com todo o respeito das peculiaridades de cada comunidade - elaborar lista das que seriam beneficiadas pelo projeto, estruturar cronograma de visitações e determinar os espaços que receberiam cada grupo de alunos dentro de cada comunidade.

Mas, ainda havia um problema: onde conseguir os livros para o projeto? Tinha-se em mente que o ideal seria doá-los à comunidade onde cada leitura foi realizada, para que as crianças pudessem reler o material após o fim do projeto, que representaria assim apenas a semente para despertar do interesse pelo mundo mágico da leitura. Este problema foi solucionado da seguinte maneira: decidiu-se organizar uma grande arrecadação de livros, via doação, na UniCarioca.

O treinamento dos voluntários foi realizado na primeira semana de junho de 2015 dentro da Instituição. Foram seis horas de reunião. Durante o treinamento por mim estruturado e ministrado, abordei questões éticas, técnicas e estéticas - associadas à impostação de voz, à postura ao ler/declamar (originárias do teatro), à dança, à leitura, à maquiagem, à improvisação, à música, ao modo de se colocar diante das mais diversas pessoas ou diante de hostilidades, etc.

Durante o treinamento, os voluntários destacaram-se em diferentes aspectos. Tendo em mente as potencialidades e o perfil de cada aluno (ao final do curso, permaneceram 48), foram então criados grupos de 5 a 7 discentes em equipes de produção, de "contação" de histórias.

Destaca-se que uma equipe de suporte/monitoramento foi montada para auxiliar os voluntários a lidarem com problemas diversos - esclarecimento de dúvidas dos voluntários relacionadas a questões éticas, técnicas, de logística, etc. A ciência de tal equipe de apoio - por mim coordenada - foi fundamental para que os voluntários pudessem se sentir seguros tecnicamente falando.

Na segunda semana de junho, após o treinamento dos voluntários, foi realizada uma grande arrecadação (durante duas semanas) de livros nas diversas unidades da UniCarioca (Méier I, Méier II, Rio Comprido e Bento Ribeiro). O NASA ofereceu espaço físico para receber os livros arrecadados (foram arrecadados mais de 5.000), e os voluntários treinados (já a caráter - com figurino apropriado) ficaram responsáveis pelos postos de arrecadação. Por vezes, tais voluntários realizaram leituras de poemas, de trechos de livros, no intuito de incentivar a arrecadação.

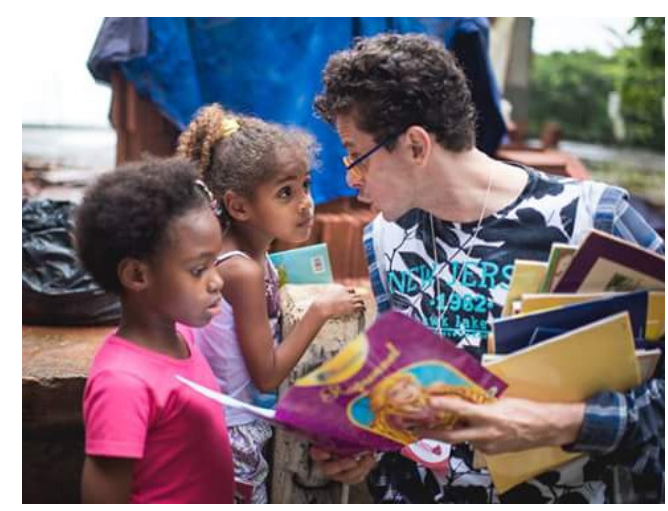

Figura 1: projeto sendo implementado 
Em parceria com o Rio Mais Social, que nos informava semanalmente o nível de segurança nas comunidades, os quatro finais de semana (de julho de 2015) selecionados para desenvolvimento do projeto transcorreram sem grandes problemas. Das 14 visitas programadas, apenas duas foram reagendadas - uma por conta de confronto, outra por conta de deslizamentos em razão de fortes chuvas.

Cada comunidade visitada recebeu, horas antes, uma equipe de produção para realizar a preparação do ambiente - leia-se cenografia e produção. Músicas, instrumentos musicais, decorações e espaços para que as pessoas pudessem se sentar foram produzidos antes da chegada das equipes de contadores de histórias, que se apresentaram a caráter - fantasiados para encarnar personagens diversos das histórias selecionadas a serem contadas.

As histórias, como já mencionado, tinham sempre cunho educativo e transmitiam lições de moral ou de motivação/inspiração. Pouco mais de 2.550 pessoas - entre idosos, adultos, jovens e crianças - participaram como ouvintes das "contações", que, longe de serem passivas, eram interativas, pois a produção sempre organizava os espaços com instrumentos de música. Pessoas de todas as idades interagiram para reforçar musicalmente momentos de suspense, de revelação, momentos lúdicos ou mágicos associados às histórias contadas.

Todo este trabalho de produção, figurino e cenografia teve como propósito a desconstrução do ambiente imediato, ou seja, todos os que estavam presentes à "contação" de história eram transportados para outro lugar, um lugar lúdico, distante do cotidiano. Durante todo o tempo, o trabalho foi monitorado/acompanhado pelo grupo de suporte/monitoramento (por mim coordenado). Tal grupo chegou a visitar três comunidades em apenas um dia, por conta do fato de que havia, naquele dia, eventos em três comunidades diferentes.

\section{A metodologia utilizada}

Cosson (2009, p. 65), disserta acerca das quatro etapas associadas à preparação do aluno/ouvinte para que ele possa de fato "entrar" na historia contada: (1) motivação (normalmente, essa etapa se dá de forma lúdica, com uma temática relacionada ao texto literário que será lido e tem como objetivo principal incitar a leitura proposta);(2) introdução (momento em que é feita a apresentação do autor e da obra); (3) leitura do texto em si (que deve ter um acompanhamento do professor. Esta etapa possui intervalos e, durante estes intervalos, há a possibilidade de aferição da leitura, esclarecimento de dificuldades relacionadas à compreensão de vocabulário ou mesmo de partes do texto) e (4) interpretação (que acontece em dois momentos - um interior e outro exterior. O momento interior compreende a decifração e é chamado de "encontro do leitor com a obra"; não pode, de forma alguma, ser substituído por algum tipo de intermediação, como resumo do livro, filmes ou minisséries. Já o momento exterior é a "materialização da interpretação como ato de construção de sentido em uma determinada comunidade”).

A despeito das dificuldades práticas vivenciadas, os contadores de histórias deste projeto buscaram, em campo, trabalhar com estas etapas propostas por Cosson.

Outra peculiaridade acerca do campo desta pesquisa relaciona-se ao fato de que se baseou em modelo metodológico polissêmico, pois se conjugaram (1) modelo do Trabalho Social Comunitário (com o propósito de sensibilizar), (2) modelo de narrativa autobiográfica (e estas narrativas a posteriori alimentaram o desenvolvimento deste artigo) e (3) modelo ecológico, com vista a estimular mudança comunitária, através do lúdico proposto pela "contação" de histórias.

O projeto aqui apresentado foi dividido em duas etapas, assim chamadas: a estruturação e o desenvolvimento/empoderamento.

Para além, destaca-se que este projeto valeu-se de pesquisa bibliográfica secundária (consultas em livros diversos que se encontram registrados na bibliografia). 


\section{Fundamentação teórica}

\section{O marketing social $x$ marketing societal}

O homem só é superiormente feliz quando é superiormente civilizado. Estas palavras são de Jacinto, protagonista da obra 'As cidades e as serras' de Eça de Queiroz. A analogia que Queiroz faz sobre a felicidade e a civilidade nos faz refletir a respeito do fato de que para se viver em sociedade de maneira harmônica e feliz, necessita-se civilidade, que é o respeito pelas normas de convívio entre os membros de uma sociedade organizada.

Todavia, uma empresa que trabalha apenas com respeito às leis, pratica a ética mínima. Para uma empresa ser considerada ética de verdade ela precisa ir além do respeito apenas às normas.

Marketing social foi um termo que surgiu em 1971, para descrever o uso de princípios e técnica de marketing para a promoção de uma causa, ideia ou comportamento social [por fatores que não se relacionam a questões legais, mas sim a questões identitárias]. "O marketing social reúne os melhores elementos das abordagens tradicionais da mudança social num esquema integrado de planejamento e ação e aproveita os avanços na tecnologia das comunicações e na capacidade de marketing" (KOTLER e ROBERTO, 1992, p.25).

Tal conceito acabou sendo absorvido por instituições diversas para que estas pudessem promover imagens perante a sociedade em consonância com os valores éticos e morais.

Massó (1998, p.7) reflete a respeito do termo marketing social e afirma que tal termo engloba as atividades que este desenvolve para obter o compromisso dos consumidores com um determinado comportamento de interesse social, favorecendo, ao mesmo tempo e de forma direta, tanto os interesses da empresa, quanto a sua posição no mercado. Zenone corrobora a afirmação de Massó ao afirmar:

O conceito de marketing social sustenta que a organização deve determinar as necessidades, desejos e interesses dos mercados-alvo e então proporcionar aos clientes um valor superior, de forma a manter ou melhorar o bem-estar do cliente e da sociedade. A administração de marketing concentra-se em equilibrar três fatores ao definir sua política de mercado: os lucros da empresa, os desejos do consumidor e os interesses da sociedade.(ZENONE, 2006, p. 65-67)

Zenone reflete sobre o laço entre instituições e a sociedade na qual estas se encontram inseridas. Faz-se necessário deixar de priorizar a mídia convencional de marketing, para investir em algo que possa dar mais consistência à imagem que a empresa deseja passar e perpetuar ao longo dos anos, tendo em vista que esse processo se caracteriza por ser de longo prazo.

[...] O marketing social tem as seguintes características: (a) o marketing social é focado em pessoas, seus desejos e necessidades, aspirações, estilos de vida, liberdade de escolha; (b) o marketing social busca mudanças comportamentais agregadas, com prioridade para segmentos da população ou mercados, não indivíduos, como foco dos programas.(GORDON, 2011 apud MORAES et al, 2012)

Por conta destas características, entender esse processo como parte integrante da estratégia geral da empresa é de suma importância para sua efetivação e bom resultado. O marketing com causa pode ser considerado uma alternativa operacional social ao marketing tradicional e, se for corretamente integrado à personalidade da empresa, conferirá vantagens diversas, interna e externamente. 


\begin{tabular}{|l|l|}
\hline Nível externo & Nível interno \\
\hline Posicionamento diferenciado da marca & $\begin{array}{l}\text { Cumprir com a função } \\
\text { social da empresa }\end{array}$ \\
\hline $\begin{array}{l}\text { Apoio ao lançamento } \\
\text { de novos produtos }\end{array}$ & Proporcionar valor agregado aos acionistas \\
\hline Captação de 'novos clientes & Afiançar a lealdade e compromisso dos parceiros \\
\hline $\begin{array}{l}\text { Aumento da influência da } \\
\text { empresa na sociedade }\end{array}$ & Desenvolver estratégias de mercado inovadoras \\
\hline $\begin{array}{l}\text { Melhores contratos } \\
\text { publicitários }\end{array}$ & Melhora na comunicação e no clima de trabalho \\
\hline Melhora da imagem da marca & Fomentar a cultura corporativa \\
\hline Melhora na imagem corporativa & Melhor posição competitiva \\
\hline $\begin{array}{l}\text { Contribuição à } \\
\text { identidade corporativa }\end{array}$ & $\begin{array}{l}\text { Incrementar a motivação } \\
\text { dos parceiros }\end{array}$ \\
\hline Melhorar a relação com o mercado & Apresentar balanços positivos \\
\hline Aumento da base de dados & Obtenção de incentivos fiscais \\
\hline $\begin{array}{l}\text { Melhora das relações com sindicatos e asso- } \\
\text { ciações }\end{array}$ & $\begin{array}{l}\text { Criação de valores } \\
\text { mais abrangentes }\end{array}$ \\
\hline Fidelidade do cliente atual & Maior retorno interno \\
\hline $\begin{array}{l}\text { Acesso forte aos formadores } \\
\text { de opinião }\end{array}$ & $\begin{array}{l}\text { Satisfação e autoestima } \\
\text { dos parceiros }\end{array}$ \\
\hline Tamanho de notoriedade & Fortalecimento da marca \\
\hline Abertura a novos segmentos de mercado & Desenvolvimento estratégico e pessoal \\
\hline
\end{tabular}

Fonte: IZQUIERDO, 2000, p. 43 a 52.

Uma instituição, ao valer-se de estratégias de marketing social, precisa estar ciente de que ações desta envergadura não podem ser isoladas - devem estar em consonância com seus valores, sua cultura, sua missão e sua visão.

Para Drucker (1997, p.70-71), não é mais possível pensar que uma empresa tem somente a responsabilidade do desempenho econômico. Os novos questionamentos e exigências dos consumidores caminham para a prática do consumo solidário e o consumidor tem consciência de que o ato do consumo é a etapa final do processo produtivo, pois, ao consumir, conforme argumenta Guedes (2000, p.11), as pessoas contribuem para preservar ou destruir os ecossistemas, manter empregos ou gerar desempregos; colaborar com a manutenção da exploração dos trabalhadores em uma sociedade capitalista e injusta ou colaborar para a eliminação de toda a forma de exploração dos seres humanos e para a construção de uma nova sociedade colaborativa e solidária.(MORAES et al., 2012)

Assim, ações de responsabilidade social geram benefícios não só para as instituições que a adotam, mas para seus consumidores, que acabam por desenvolver atitude positiva em relação à instituição e a seus produtos/ serviços. Essa postura, segundo Meira (2004, p.1, apud MORAES, 2012), é por vezes chamada de marketing societal (com preocupação social e ambiental), outras vezes de marketing de causa, ou simplesmente, marketing com responsabilidade social. 


\section{A contação de histórias como estratégia de marketing social ou societal}

A contação de histórias é uma arte milenar e foi essa arte a estratégia de marketing social (ou societal) adotada pela IES aqui mencionada para atuar de maneira ecológica, respeitando aspectos sociais, culturais e relacionais das comunidades abraçadas pelo presente projeto.

Povos valem-se, há séculos, deste tipo de arte para rituais, festas. Contadores procuram representar, enfatizar vivências pessoais, grupais, culturais. Ao longo da história, essa arte foi sofrendo alterações, graças ao advento das novas tecnologias. Donato (2005) afirma que as novas mídias, como a televisão, o cinema e a internet, praticamente baniram a "contação" de histórias dos encontros sociais. Isso porque, com a força da imprensa, os livros e os jornais tornaram-se os grandes agentes culturais dos povos, graças ao alcance maior e mais eficaz que apresentam, porém perderam-se, com isso, questões associadas à regionalidade.

A arte continua viva em pequenos círculos, mas precisou ser reestruturada para que pudesse se manter presente nos grandes centros urbanos. Uma das estratégias utilizadas pelos contadores de histórias foi a adoção de técnicas de teatro e leitura e também a utilização de vivências de grandes autores em detrimento do uso das experiências pessoais. Esta mudança gerou dois rápidos resultados: aumento da socialização presencial entre pessoas diversas em ambientes direcionados à prática da arte e o empoderamento dos contadores.

Segundo BAUMAN (2003, p. 9), a imaginação, diferente da dura realidade da vida, é produto da liberdade desenfreada. Podemos "soltar" a imaginação, e o fazemos com total impunidade - porque não teremos grandes chances de submeter o que imaginamos ao teste da realidade. Essa frase pode ser usada para ilustrar a sensação que a "contação" de histórias procura levar a sua plateia, por vezes restrita a uma difícil realidade imposta pelas duras condições da vida.

\section{Letramento e poder via contação de histórias}

Segundo Street (2003), letramento responde pelos conhecimentos que veiculamos via escrita, pelos modos como usamos a escrita para nos comunicarmos e nos relacionarmos com as outras pessoas, pela maneira como a escrita é usada para dizer e dar forma ao mundo. De fato, a leitura e a escrita atravessam a existência das mais variadas maneiras e são de vital importância para o desenvolvimento cognitivo dos seres humanos.

O conceito de letramento destaca-se, está imbricado ao conceito de aprendizagem. Enquanto o último relaciona-se à didática, ao ensino, ao ato de ler e escrever, o primeiro está associado à vivência, à leitura e à escrita dentro do contexto social, ao envolvimento dos indivíduos com a sociedade.

Francis Bacon (1561-1626), influenciado pelo espírito do empirismo, procurava não um saber contemplativo ou desinteressado; ele buscava um saber que não tivesse um fim em si, ou seja, buscava saberes instrumentais, pois compreendia o conhecimento como instrumento ou ferramenta de poder. Pode-se dizer que o letramento, na medida em que se relaciona à capacidade de ler, aprender e apreender através da leitura, propõe saberes instrumentais e pode ser compreendido, também, como instrumento de poder.

A ação ecológica e social aqui narrada valeu-se da "contação" de histórias para viabilizar letramento literário aos jovens das comunidades que sediaram este projeto, para empoderar. Isto porque, conforme já mencionado, o termo letramento pode ser utilizado para designar, dentro do contexto social, absorção de conhecimentos, via leitura, via processos de interação.

Assim, a "contação" de histórias - elemento fundante deste projeto - ao propiciar o contato de jovens e adultos de comunidades de baixa renda com a leitura, atuou com letramento literário (clássicos da literatura brasileira), em prol da ampliação de suas bagagens culturais e, com isso, buscou viabilizar o desenvolvimento de suas autoestimas e, por conseguinte, a ampliação de seus horizontes de vida. 
A noção de letramento mostra-se bastante pertinente dentro do contexto educacional brasileiro para a compreensão da dimensão política das praticas de alfabetização, tanto na perspectiva de quem ensina como na de quem aprende (SOARES, 1998; GOULART, 2003), haja vista que, de acordo com a Pesquisa Nacional por Amostra de Domicílio (Pnad), o analfabetismo entre jovens e adultos caiu de 11,5\% em 2004 para 8,7\% em 2012. Essa redução revelou-se mais intensa no Norte e Nordeste, onde estão localizados os maiores índices de analfabetismo do país.

\title{
O desenvolvimento cognitivo propiciado pela contação de histórias à luz das teorias de Vygotsky
}

Lev Semenovitch Vygotsky, mais conhecido como Vygotsky, psicólogo bielo-russo, que nasceu na cidade de Orsha em 17 de novembro de 1896 e morreu aos 61 anos na cidade de Moscou, em 11 de junho de 1934, postulou sobre o desenvolvimento cognitivo do ser humano a partir dos vieses social, cultural e ambiental.

Vygotsky nos faz refletir a respeito do processo de aprendizado das crianças, bem como da importância do contexto histórico no qual o aprendizado está inserido.

Cada criança tem sua bagagem e seu repertório de conhecimentos adquiridos na vivência (através de experiências tácitas e explícitas em um contexto histórico e cultural particular) e, conforme recebe mais dados e informações, absorve-os e trabalha para apreendê-los; chamamos a este processo de sociointeracionista.

É por meio de outros, por intermédio do adulto que a criança se envolve em suas atividades. Absolutamente, tudo no comportamento da criança está fundido, enraizado no social. Assim, as relações da criança com a realidade são, desde o início, relações sociais. (VYGOTSKY, 1984, p. 281)

Para Vygotsky, a diferença entre o conhecimento já sedimentado e o conhecimento em processo de sedimentação revela o potencial daquela criança para se desenvolver. Para além, Vygotsky afirma que não há como transpor expedientes de aprendizagem; portanto, cada etapa de aprendizado e de apreensão do conhecimento precisa ser vivida pelo indivíduo - tem-se, desta maneira, um processo dinâmico e linear.

Assim, segundo Vygotsky, poder-se-ia dizer que o desenvolvimento cognitivo do indivíduo se dá por meio da interação social - vivências tácitas e explícitas - leia-se aqui interação com os outros e a leitura. Neste sentido, a "contação" de histórias propiciada por este projeto pretende auxiliar no desenvolvimento cognitivo dos jovens e adultos das comunidades que sediaram este projeto.

\section{O campo: a comunidade}

O artigo 147 do Plano Diretor do documento que sistematiza o projeto Favela-Bairro afirma que, para fins de entendimento,

\begin{abstract}
favela pode ser definida como área predominantemente habitacional, caracterizada por ocupação da terra por população de baixa renda, precariedade da infraestrutura urbana e de serviços públicos, vias estreitas e de alinhamento irregular, lotes de forma e tamanho irregulares e construções não licenciadas, em desconformidade com os padrões legais.(BRASIL, 1992, p. 67)
\end{abstract}

Essa definição traduz espaços carregados de tensões estruturais. De certo que as favelas possuem suas tensões latentes e manifestas oriundas, entre outras coisas, de limitações e deficiências estruturais, mas estão carregadas também de solidariedade, de humanidade e de indivíduos impregnados por sensação de pertencimento ao todo, de pertencimento a favela, ou melhor - ao termo utilizado por muitos moradores para se referirem às favelas nas quais vivem - comunidade.

[Comunidade], o que essa palavra evoca é tudo aquilo de que sentimos falta e de que precisamos para viver seguros e confiantes. [...] Na comunidade, podemos relaxar, pois nos sentimos seguros, não há perigos ocultos em cantos escuros - aliás, com certeza, dificilmente há "canto escuro" na comunidade. Bauman afirma que o conceito de comunidade é repleto de idealismo e, exatamente por isso, torna-se 
inalcançável. A comunidade estaria, então, situada no campo do eterno devir (BAUMAN, 2003, p. 0708).

Mas, apesar da advertência de Bauman, dar-se-á realmente preferência ao termo comunidade, que possui uma conotação mais humana, mais segura, mais familiar. Isto porque notou-se, nas 14 comunidades visitadas, o orgulho dos locais pelos espaços que habitam - alta percepção de segurança e de pertencimento a um espaço protegido, familiar. Assim, ao invés de favela, dar-se-á preferência, aqui, pelo uso da palavra comunidade.

\section{Conclusões}

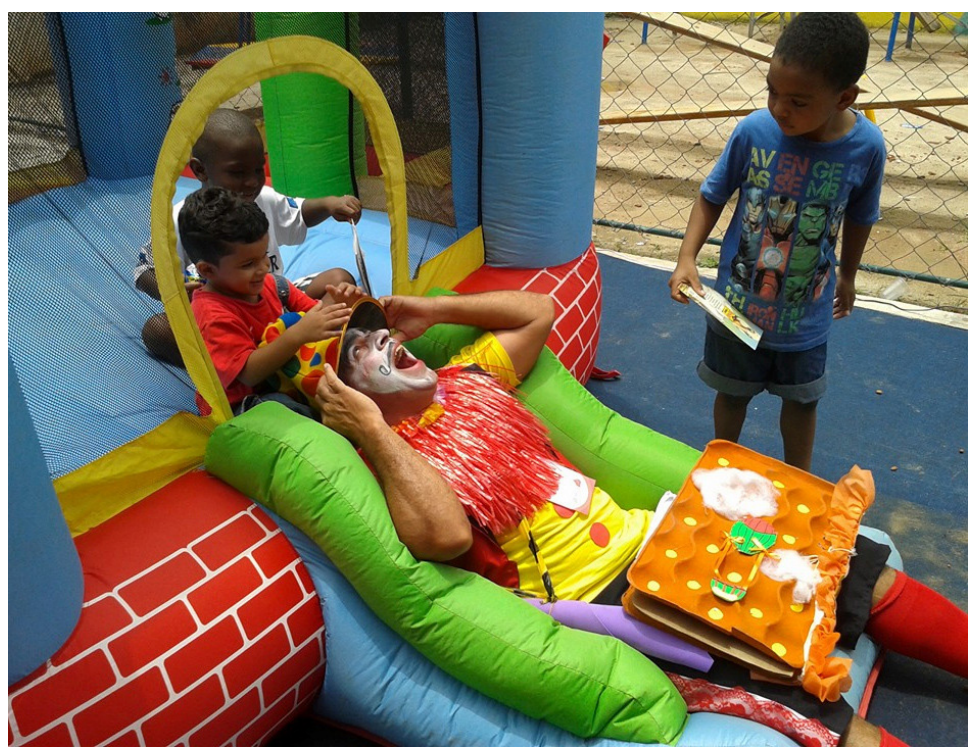

Figura 2: Projeto sendo implementado.

Identificaram-se diferenças significativas entre as comunidades visitadas que se situam na Zona Sul e na Zona Norte do Rio de Janeiro. Eis algumas: assistência da prefeitura nessas localidades, hábitos e comportamentos dos moradores para com os turistas ou visitantes, vulto e quantidade de projetos sociais, reflexos dos conflitos derivados do tráfico. Nas comunidades da Zona Sul nota-se maior presença da prefeitura e de visitantes (ou turistas), percebe-se projetos sociais mais bem estruturados, provenientes também da iniciativa privada, mas em contrapartida, também se percebe maior presença do tráfico.

Todavia, apesar das peculiaridades associadas a cada comunidade, percebeu-se que a interação entre voluntários do projeto e ouvintes promoveu impactos positivos nos dois grupos (que integraram os 14 eventos). Contadores voluntários e produtores voluntários, ao se engajarem neste projeto, trabalharam de forma tácita aspectos interacionais, éticos e morais. Já entre os ouvintes, percebeu-se que crianças (acompanhadas de seus responsáveis) inicialmente se mostravam ariscas, amuadas, recebiam as equipes de "contação" do circuito com olhar desconfiado, mas, ao final das atividades, revelavam largo sorriso. Idosos, adultos e jovens também revelaram grandes mudanças comportamentais após os eventos. 


\begin{tabular}{|l|l|}
\hline Envolvimento & Comunidade \\
\hline Alunos & $\begin{array}{l}\text { 2.550 crianças participaram dos ambientes de contação em escolas, creches } \\
\text { e praças das comunidades }\end{array}$ \\
\hline $\begin{array}{l}\text { do treinamento alunos participaram } \\
\text { dos eventos de contação } \\
\text { de histórias }\end{array}$ & $\begin{array}{l}450 \text { casas foram visitadas pelos contadores em homenagem aos } 450 \text { anos do } \\
\text { Rio de Janeiro }\end{array}$ \\
\hline
\end{tabular}

Observou-se que - de maneira geral - as crianças das diversas comunidades envolvidas no projeto (praticamente $80 \%$ do público que compareceu aos eventos de contação de histórias) tinham perfis muito parecidos: revelavam amadurecimento precoce, possivelmente proveniente da rotina do dia a qual são submetidas. Elas não apenas precisavam estudar, mas muitas delas precisavam também cuidar das suas casas e de seus irmãos menores para que seus pais pudessem trabalhar. Esta realidade gerou reflexos no operacional do projeto, uma vez que após uma ou duas histórias, diversas crianças verbalizavam: Eu não posso ficar aqui, tio (sic), porque tenho muitas coisas para arrumar em casa. Durante as leituras, diversas crianças entravam e saiam, mas, de fato, poucas permaneceram por tempo prolongado. Assim, mesmo que por tempo limitado, este projeto somou esforços para propiciar às crianças das comunidades envolvidas momentos leves, divertidos, lúdicos.

Pico della Mirandola (BAUMAN, 2003, p.23) afirma que sua vontade determina seus limites. Ou seja, como artífices livres e soberanos, podemos construir nossas próprias histórias e, ao participarmos deste projeto como contadores, produtores, ou ouvintes, todos nós pudemos deixar de lado, por algumas horas, a realidade imediata, para nos concentrarmos em aprendizado lúdico, para nos concentrarmos na expansão dos nossos limites sonhados.

Observou-se, em cada uma das 14 favelas visitadas, o orgulho que cada morador possui de sua comunidade, mas também a descrença que possuem em relação a ações externas, uma vez que, geralmente, as ações sociais implantadas nesses lugares são iniciativas dos próprios moradores. Todavia, estas ações locais são voltadas - na maioria das vezes - para sanar questões estruturais emergenciais locais - questões socioambientais relativas à coexistência destes em equilíbrio com o meio ambiente no qual habitam.

Este projeto de marketing social, ou marketing societal, gestado pelo EPM/ UniCarioca e pelo NASA/UniCarioca operou em consonância com seus valores éticos e morais - e.g.: inclusão social (ao propor letramento literário aos moradores de baixa renda de comunidades cariocas, visando à ampliação de suas potencialidades), educação transformadora (a todos os envolvidos no projeto, cada qual de maneira peculiar) - e fundamentou-se no letramento, uma vez que procurou, via interação social dinamizar as relações de poder locais a partir de estímulos lúdicos e realizou tudo isso considerando Vigotsky, pois partiu do expediente de conhecimento dos locais para propor novos aprendizados relacionados a aspectos morais, éticos, recreacionais, lúdicos.

Cada um dos envolvidos no projeto (contadores de histórias, alunos e profissionais da UniCarioca) colocou na ação o que podia, pois o mediador só pode dar o que ele tem (PETIT, 2009, p. 239). Não se teve aqui a intenção de narrar um projeto que pretendia reparar desordens ou desigualdades do mundo. Cada mediador envolvido no processo procurou atuar com uma esperança crítica para transcender fatalismos, desesperanças e pessimismos, rumo a horizontes de expectativas esperançosas, mas não ingênuas (FREIRE, 2005). No fundo, desejou-se, aqui, com este projeto, a abertura de um espaço de possibilidades e de esperança para que os jovens das 14 comunidades que atenderam ao evento não acabem por percorrer fatidicamente o caminho que vai da pobreza aos grupos armados e depois à delinquência, e desta à morte precoce ou à prisão (PETIT, 2009, p. 239). Acredita-se ou, pelo menos, espera-se que este projeto tenha contribuído para somar esforços a um trabalho de redesenho de fronteiras e possibilidades.

Destaca-se, por fim, que este projeto não tem a intenção em apresentar conclusões ou encerrar discussões acerca dos assuntos aqui tratados, antes, pretende adensar discussões a respeito dos assuntos que abordou. Para além, a simplicidade do projeto permite que ele seja replicado por entusiastas. 


\section{Referências Bibliográficas}

BAUMAN, Zygmunt. Comunidade. A busca por segurança no mundo atual. Rio de Janeiro: Zahar, 2003.

CAVALLIERE, F; VIAL, A. A nova classificação de favelas para o planejamento das políticas públicas. In Atas de reuniões: conselho estratégico de informações da cidade. Prefeitura da cidade do Rio de Janeiro, 21 de setembro de 2012. Acesso em 06/05/2016. Disponível em <http://www.rio.rj.gov.br/documents/91329>.

COSSON; RILDO. Letramento literário: teoria e prática. São Paulo: Editora Contexto, 2009.

DRUCKER, P. F. Administração de Organizações sem fins lucrativos: Princípios e práticas. $4^{\circ}$ edição. São Paulo: Pioneira, 1997.

FREIRE, Paulo. Pedagogia da esperança: um reencontro com a pedagogia do oprimido. Rio de Janeiro: Paz e Terra, 2005.

IZQUIERDO, G.B. El valor de compartir beneficios - las ONGD y el marketing con causa: retos y oportunidades. Bilbao: Universidad de Deusto, 2000.

KOTLER, P.; FOX K. F. A. Marketing estratégico para instituições educacionais. São Paulo: Atlas, 1994.

KOTLER, Philip; ROBERTO, Eduardo. Marketing Social, estratégias para alterar o comportamento publico. $1^{\text {a }}$ Ed. Rio de Janeiro: Campus, 1992.

KOTLER, Philp. Marketing Social, São Paulo: Atlas, 1999.

KOTLER, Philp. Marketing. São Paulo: Atlas, 1986.

LATAILLE, Yves et al. Piaget, Vygotsky, Wallon: Teorias psicogenéticas em discussão. São Paulo: Summus, 1992.

LURIA, A. R., LEONTIEV, A. N. Linguagem, desenvolvimento e aprendizagem. São Paulo: Icone/EDUSP, 1988.

MASSÓ, G. R. El beneficio de compartir valores - marketing social corporativo, una nueva estrategia para diferenciar las marcas. Bilbao: Deusto, 1998.

MORAIS, Rosa; GIULIANI, Antonio; PIZZINATTO, Nadia; CUNHA Christiano; CORREA, D. A. Marketing e Responsabilidade Social Corporativa: as expectativas dos gestores e a ótica dos consumidores. Piracicaba: UNIMEP. 2 ème Congrès TRANSFORMARE 19 - 20 mars 2012, Paris. Acesso em 06/06/2016. Disponível em: <www.transformare.adm.br/anais/Marketing-social-RosaMoraes.pdf $>$.

MORCERF, S.O.; ALMEIDA, T.C. S. Marketing Social - A Estratégia de Mudança Do Comportamento Social. Volta Redonda: Cadernos UniFOA, Ano 1, № . 1, Jul. 2006. Acesso em 20/04/2016. Disponivel em: <http://www.unifoa.edu.br/pesquisa/caderno/ edição/01/71.pdf>

MOREIRA, Marco Antônio. Teorias de Aprendizagens. São Paulo: EPU, 1995. Acesso em 06/05/2016. Disponível em: <http:// www. fisica .net/monografias/Teorias_de_Aprendizagem.pdf $>$.

PETIT, Michèle. A arte de ler - ou como resistir à adversidade. 1a. Edição. São Paulo: Editora 34, 2009.

POZO, Hamilton; TACHIZAWA, Takeshy; SOUZA, Jose Henrique. Responsabilidade social corporativa e marketing Social: um estudo exploratório em empresas da Baixada santista. Campinas: FACCAMP (Faculdade Campo Limpo Paulista), PUC-CAMP (PUC Campinas Campo Limpo Paulista), 2008. Acesso em 13/05/2016. Disponível em : <http://www.unisantos.br/pos/revistapatrimonio/images/artigos/Artigo1_JanFevMar08.pdf>.

SILVA, Ezequiel Theodoro da. Dossiê Temático Leitura e formação de professores: ENTREVISTA COM O PROFESSOR EZEQUIEL THEODORO DA SILVA. Uberaba: RPD (Revista Profissão Docente), V.12, No. 26 (Jan/Jun), 2012. P.115-119 (ISSN 1519-0919). Acesso em: 20/03/2017. Disponível em: <http://www.revistas.uniube.br/index.php/rpd/article/viewFile/564/634>.

STREET, Brian. Abordagens alternativas ao letramento e desenvolvimento. In: Anais da Teleconferência UNESCO Brasil sobre "Letramento e Diversidade", 2003.

SOARES, Magda Becker. Letramento: um tema em três gêneros. Belo Horizonte: Autêntica, 2003.

VYGOTSKY, L.; LURIA A. R.; LEONTIEV, A. N. Psicologia e Pedagogia. Lisboa: Estampa, 1977.

ZENONE, L. C. Marketing Social. 1ª edição. São Paulo: Editora Thomson, 2006. 